\title{
Commentary
}

\section{Getting geography into the media: understanding the dynamics of academic-media collaboration}

\author{
FRANCES HARRIS \\ School of Geography, Geology and the Environment and Centre for Earth and Environmental Science \\ Research, Kingston University, Penrhyn Road, Kingston-upon-Thames, Surrey KT1 2EE \\ E-mail: f.harris@kingston.ac.uk
}

This paper was accepted for publication in November 2010

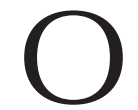
n 5 August 2008, the UK's BBC News at Ten began with a headline concerning a new map showing competing claims for territory in the Arctic Ocean developed by the International Boundaries Research Unit at Durham University (BBC 2008). Surely this was the Holy Grail of media impact? The highly visual item, itself the product of academic research, was being used on a primetime news television programme which generated a great deal of interest in both the subject matter (Dodds 2010) and the map itself.

Environmental and geographical issues are gaining wider attention from the public, as many of the critical issues facing society today are embedded in this academic area. Whether people are concerned with climate change, recycling, urban expansion, new towns or preserving the countryside, geography and environmental science can make a contribution to the debate (e.g. Anderson et al. 2008; Wilson 2010; Hulme 2010; Davies 2008). Even in our homes and kitchens, as we consider what to eat and what to wear, we are making choices that affect food producers and factory workers throughout the world (e.g. EdwardsJones et al. 2009). Geography is well placed as a discipline to address these issues, from the science behind them to the social and economic issues arising from these developments.

I have always been interested in public understanding of science, and the role that the media can play in reaching out to the public and informing them about the key scientific debates and developments which will affect their lives. This is particularly true with respect to rapidly changing debates concerning global and environmental issues. Universities teach undergraduates and postgraduates about these issues, but formal educational establishments can do comparatively little to reach out to those out of education. For many people, they stop studying science at school or university, in their teens or early twenties. However, for the remainder of their lives (easily 50-60 years) new developments in science and technology continue at great pace, and they are left grappling with the issues and complexities without much guidance. The media can play a role here, reaching out to people in their homes through radio, television, newspapers and magazines, to keep the public abreast of new issues. In addition to these traditional forms of media, new modes of engagement through the web via blogs and podcasts (see Maddrell 2010 for some geographical examples), as well as twitter, are increasingly playing a role. There has been a surge in geographical programmes on UK terrestrial television channels, with major series such as Coast (now making its fifth series, and repeated more than any other programmes). Perhaps we should be asking who interprets the science into understandable, digestible and interesting packages to engage the wider public and make them aware of new developments and issues and how do geographers get into the position of making programmes?

There is a growing number of papers concerning geography's reach (Merriman 2010; Gardner et al. 2010) alongside wider debates about geography's relevance (especially relating to its influence on policy; e.g. Maddrell 2010; Ward 2005; Dorling and Shaw 2002; Murphy et al. 2005; Massey 2001; Martin 2001). Increasing the public profile of geography as a discipline is a common goal. In the current context which promotes communication and dissemination of results and demonstration of 'impact', reaching beyond the academy is important. It may be unrealistic to predict the impact of research at its outset (Phillips 2010), but research councils, guided by the Higher Education Funding Council for England, are seeking to quantify impact. This can include requesting information on media reporting, TV and radio interviews, as well as public engagement events 
(RCUK nd). Geography academics are being asked to be more outward facing, show relevance of funded research, and engage the public (Maddrell 2010).

The media can parachute the results of geographical research into households through television, radio or newsprint. As Gardner et al. (2010) point out, concluding research with policy recommendations is not necessarily the same as attracting the attention of policymakers. However, many policymakers and politicians listen to what is in the news, and what issues have the ear of the public, and so getting research into the media can increase its profile with the target audience. The key to this is understanding how the media works, and what they are looking for when making programmes.

Creating science programmes for the media is challenging, largely because it brings together two groups of people who generally do not have much common background, to develop a programme for a wider audience that it is assumed will have little or no scientific knowledge. Such a process is similar to the many challenges facing interdisciplinary research projects within academia: bring together groups with different approaches to tackling problems, groups who use a different language (with respect to key phrases and common concepts) and set of reference points for communication (Harris et al. 2009; Bracken and Oughton 2006 2009). For academics it can be challenging to present their research to a lay audience, beginning from first principles, but explaining cutting edge debates. Academics also need to understand what makes for entertainment: what will make an interesting programme, and what works when presented on radio or TV? For the media, in addition to translating detailed research into something manageable for viewers and listeners, there is also the added challenge of understanding and dealing with the conflicting theories of nuances of interpretation and differing opinions among the many academics who may be called on to make a programme.

Thus the complexity and diversity of science programmes presents challenges to the media and the researchers. While many academics would like their research to be brought to wider attention through the media, few really understand how to go about this, what will make it attractive to media companies, and how, finally, to explain their work to cameras and microphones. This translation of their research from academia to a lay audience requires a transdisciplinary approach that bridges the boundaries of academy and practice. The programme makers must bring together different methodological approaches, integrate the results of many researchers, sometimes carried out at different scales, so that scientific advances overall can be explained simply and clearly to the public.

In 2008, I was fortunate to have a British Science Association (BSA) media fellowship. Each year, this programme embeds about 15 scientists from aca- demia into media organisations for periods of about 2-8 weeks during the summer. At the end of the summer, all media fellows attend the BSA science communication conference, and play a role in reporting the results, working alongside professional journalists. This experience provided an insight into what the media are looking for when making science or news programmes. Given my background as an environmental scientist focussing on food and farming issues, I was placed with Radio 4's programmes Costing the Earth and Farming Today. Farming Today is a 15-minute news programme, broadcast at 5:45 am, sandwiched between morning prayer, and the Today programme. It has a listenership of just under one million listeners a week ${ }^{1}$, including politicians and policymakers, as well as many early morning commuters. Despite its title, it focuses on wider rural issues. Costing the Earth is a half-hour environmental programme, broadcast in the evening, focusing on one topic each week. Both are available on BBC i-player for those who missed the programme or wish to listen again. Listeners may also choose to receive Farming Today as a regular podcast.

Working in radio presented a specific set of challenges from the start. Clearly, no images can be used. Pictures, diagrams and maps are ruled out. Secondly, there can be no silences. In television, commentary can be slow, while the camera shows the view, or observes, but in radio, a silence of a few seconds sounds like a break in transmission. Staff at the BBC kept referring to radio programmes having 'colour', which is about providing a sense of place through background noise, narrating what the presenter or speaker is doing, and changing the pace of the programme, through the introduction of new voices or noises, to draw listeners back if they have become bored or distracted. (Many people listen to the radio while doing other things.) This avoids creating a programme which is just a talking voice.

News programmes such as Farming Today are made on a daily basis, with some weekly themes being developed a few weeks beforehand. Costing the Earth was made with a relatively longer lead time of 4-10 weeks, which gave more time to identify key issues and informants, hear what they have to say, and string it together into a story lasting half an hour. The timescale gave programme makers longer to research issues, and the length of the programme allowed reporters to get into more depth. Where appropriate, Costing the Earth likes to report new research: something that was fresh and not yet reported elsewhere. In several cases the content of the programme changed as it was being developed, responding to what the producer found interesting during research. The end product was quite different to the initial plan.

As a news programme, Farming Today is produced daily, and focuses on very topical issues. One of the editors defined news as information which will be old/irrelevant/uninteresting tomorrow. The team spend 
the morning reading papers and press releases to assess potential news stories. A lunchtime meeting confirms the content of the programme, and during the afternoon the programme team research the issues, and identify key speakers. They will speak to potential contributors prior to recording, to ascertain that they can make a useful contribution, and also that they can get their point across clearly and in an interesting way. The programme is recorded between 5 and 7 pm, during which time the presenter, under direction from the producer, interviews the contributors. Timing is tight, and people with a relevant contribution must make themselves available that afternoon. Stories are not held over to another day, as they become old news. Farming Today's weekly theme is chosen about 10 days in advance, and researched and prepared beforehand. This allows them to plan on-site interviews, and take more time researching and recording interviews. There is more flexibility if you are asked to contribute to this.

During my time at the BBC I was constantly comparing their working environment and practices with the university sector, where I had been working since 1992. My reflections fall under several headings.

\section{Providing context}

Academics are trained to pursue rigorous research, which involves being critical thinkers, querying sources of information, and being wary of bias. They start by reviewing what work has been done in the past, searching for seminal papers, identifying key theories, and assessing the current debates in their area. All work quoted is referenced back to the source. Thus prior to commencing research, there is a considerable amount of background work, key to justifying funding applications, and ensuring that research is not repeating what has been done beforehand, but is indeed taking things forward. However, the whole process of getting started can take quite a lot of time. Once the argument has been built up, the research can be developed to test or develop the theory, and then results analysed to see what has been found. Once done, results are presented with plenty of caveats and explanations, defining boundaries and applicability. Thus in some senses, academics focus a lot on the past.

The media, however, work in the present, preparing programmes on fairly short timeframes. Presentation is also over a shorter time period - there is no time to present the background theories, and build up to the final point. Rather, they want to make the point, and perhaps discuss its implications. This was refreshing, but did take a change of approach. Interestingly, when I asked about past work on genetically modified organisms, colleagues at the BBC suggested a database which would search and allow me to find again past broadcasts on the topic. Academics would use journals, and Google scholar. When I showed Google scholar to a BBC colleague, he had never seen it. We all live in our own worlds of networks and information sources.

\section{Access to policymakers}

As alluded to earlier, there is a growing concern about the gap between research and policymakers, particularly the likelihood of policymakers finding, reading and acting upon the recommendations arising from geographical research. In contrast, staff at the BBC who are not necessarily experts on a particular topic can ring key policymakers and speak to them regularly. During the fellowship I was telephoning key players in the farming industry on behalf of the BBC, and this meant I could discuss GM issues with those who would never normally have prioritised time to a 'lowly academic'. For example, within half an hour of leaving a message for the spokesman to the Agricultural Biotechnology Council I was called back by the man himself, who stepped out of meetings in Germany to do so. Likewise many others were keen to be in touch. Of course, no one wants the words 'unavailable for comment' mentioned in association with their name. The BBC is a national media corporation, with an international reputation. The response may not have been similar to all media organisations.

\section{Defining programme content}

Programme content was partly dictated by practical issues such as cost to make it (including proximity of locations from the BBC producer's base), and suitable setting and background. For a programme on Ecotowns we focussed on Liverpool. In addition to having plenty to offer for the programme, it also offered a single location on which the programme team and presenter could focus for one long day, rather than spending the budget on our travelling time. This meant that other interesting, and equally valuable examples, were dropped. This decision was based on logistics, rather than criticism of the other possible examples.

Many programmes are made over a short time frame. And ultimately, the length of the programme is inflexible. Thus editing does, at times, have to be ruthless. As I listened to the work of a producer, editing his material, this led to interesting discussions about what to include, what to leave out (all the scientists' caveats) and how voice and tone are important, alongside what the speaker actually says. An interesting point made in a monotone is likely to get cut.

\section{Presenters, producers and researchers}

The relationship between producer and presenter was interesting to observe. Producers and their team do a lot of background research, plan the programme, have 
a sense of what they are expecting people to say, and how the whole narrative will fit together. Presenters, who front the programme, and are the name usually most associated with the topic, are brought in as the programme is recorded. They are the voice on the programme, and the person who must ask all the questions.

Programme making was very much a team effort. Behind the producer is a team of people whose names are never mentioned on radio programmes. Researchers (as well as producers) gathered material and ideas, and then identified people who were telephoned. If people came across well on the telephone, and fitted into the programme, interviews were arranged. Presenters needed to be on hand for the interview, so arrangements had to coincide with their timetable as well. On Farming Today, someone in the team would carry out research to develop the weekly theme, and line up people to be interviewed each day. Come the final moment, everything was handed over to producers and presenters. Handing over to a producer shortly before the interview meant that both the producer and presenters had to grasp the idea of the interview quickly.

\section{Voice}

An interesting challenge was the way in which knowledge could be transmitted. Academics write papers, and control its content. In radio the key points are made by invited guests who are interviewed. The producer is relying on the interviewees to make the points and put the message across. Obviously, for material which is not going out live, the interview can be edited, but it takes careful crafting to get people to phrase things clearly, succinctly, and in an interesting manner. This is harder than when academics are preparing a talk, and inserting case studies to illustrate the point. In the radio programmes, the case studies had to make the point, as well as illustrate it. Academics lecture, producers have to find someone to say the message.

There are clear rules about bias, and presenting arguments within the media. Producers where I worked clearly tried to ensure that the material presented was unbiased, either through balancing material within a programme, or over the length of a series.

Within the BBC staff are able to move departments, either on short 6-week attachments, or on longer transfers. Thus people stepped into and out of teams, often moving from one type of programme to another. I met people who had moved from the Asian network to Costing the Earth, and from Radio 5 live to Farming Today. Academics would be unlikely to change discipline radically. They do change disciplines, using incremental steps, and with much reading and research to underpin the change. After all, they must prove themselves equal to the task in the new discipline in terms of publication and raising research funding. I found it disconcerting that science programmes would be made by people with little or no science background. There is an argument that those with some distance from the topic can see things more objectively, and present a more balanced programme, but on the other hand, some science basis is surely required to make a good science programme? The programme makers need to understand the language used by the scientists, and also the relative importance of the many caveats given when work is presented.

All of my cohort of media fellows found the experience challenging but also stimulating. While at times we found the media bewildering there was always a thrill to seeing our work in the media. Perhaps the most illuminating time was when we worked with the 'media pack' at the science festival, experiencing press conferences and trying to summarise and explain research outside of our own disciplines. This allowed us to appreciate the challenges faced by science correspondents in their daily work. Whereas academics ponder and debate, journalists submit final copy to tight deadlines.

\section{Final reflection}

While at Farming Today few of my ideas for newsworthy topics seemed to hit the mark. However, one year later, some of my own research was the subject of a routine press release from Kingston University (Harris 2009). The research concerned the educational access programme of the Department for Environment, Food and Rural Affairs (Defra), which encourages farmers to host educational visits from school children. It was a small project, but it caught the attention of the media, due to the fact that my research topic matched a wider news story about an outbreak of E. coli 157 in a petting farm at Godstone, Surrey (Bingham 2009). My research was reported in small rural newspapers and later picked up by broadsheets. I was also interviewed on Farming Today, thus ending up on the other side of the programme-making process. My previous time at the programme meant that I was more confident when speaking to the programme researchers. Media training I had had through Kingston University helped me focus my arguments and present them clearly. This meant that my interview was broadcast fully the following day, and again in the weekly summary programme. However I am under no illusions: the reason I was on the radio was timing of the E. coli outbreak, which coincided with the press release. Farming Today had not been interested in the topic when I'd suggested it a year beforehand while at the BBC. If the press release had gone out a few weeks earlier or later, I would not have featured. This illustrates the fact that there is a lot of luck in getting work into the media (a point also highlighted by others, e.g. Dodds, in Gardner et al. 2010). Godstone's misfortune (and the children affected) was the impetus for the media interest in my research. In the same way, no amount of 
brilliant research will reach the media if a major global event (e.g. 9/11, a tsunami, or a financial crisis) happens to occur on the same day.

Many academics are wary of the media. Often they are concerned that what they say will be misinterpreted. Indeed, there are often concerns about the media's interpretation of research (for example, see Jennings and Hulme 2010). As a contributor to a programme, you have no way of knowing how the contribution will be edited, or how it will be juxtaposed with other opinions when the whole programme is put together. However, an understanding of the constraints and practices of the science media can help plan for such issues. Keep it short and simple one comment I heard was to imagine you are explaining your research to your friend's mother. Avoid lots of complicated caveats, which are likely to be deleted anyway, and speak in an interesting manner, particularly if it is for radio. And above all, if your material is not used, don't take it personally, it probably either didn't fit into the recording schedule, or made the programme over run. While lectures and even conference presentations have some time flexibility, the radio programmes have to finish within 15 seconds of a specified time slot, regardless of how interesting your final point might have been.

As stated at the outset of this commentary, geographers can contribute to many of the debates facing society today. Engaging with the media is one way to broaden your audience. The media interest in my research lead to many enquiries from individuals and organisations, including one from the then shadow secretary of state for Defra, all wanting a full copy of my research report. Only time will tell if it has influenced policy.

\section{Note}

1 To put this into context, the Today programme had almost 6.5 million listeners per week, The Archers 2.3 million (internal $\mathrm{BBC}$ figures, reported to author).

\section{References}

Anderson J, Askins K, Cook I J, Desforges L, Evans J, Fannin M, Fuller D, Griffiths H, Lambert D and Lee R 2008 What is geography's contribution to making citizens? Geography 93 34-39

BBC 2008 Arctic Map shows dispute hotspots (http:// news.bbc.co.uk/1/hi/sci/tech/7543837.stm) Accessed 6 December 2010

Bingham J 2009 Godstone Farm E-coli outbreak: parents' anger that attraction stayed open The Daily Telegraph 14 September

Bracken L J and Oughton E A 2006 'What do you mean?' The importance of language in developing interdisciplinary research Transactions of the Institute of British Geographers 31 371-82

Bracken L J and Oughton E A 2009 Interdisciplinarity within and beyond geography: introduction to special section Area 41 $371-3$ and following papers

Davies A R 2008 The geographies of garbage governance: interventions, interactions and outcomes Ashgate, Farnham

Dodds K 2010 Flag planting and finger pointing: the law of the sea, the Arctic and the political geographies of the outer continental shelf Political Geography 29 63-73

Dorling D and Shaw M 2002 Geography off the agenda Progress in Human Geography 26 629-46

Edwards-Jones G, Plassmann K, York E H, Hounsome B, Jones D L and Milà i Canals L 2009 Vulnerability of exporting nations to the development of a carbon label in the United Kingdom Environmental Science and Policy 12 479-90

Gardner R, Dodds K, Souch C and McConnell F 2010 Communicating geographical research beyond the academy. A guide for researchers RGS (with IBG), London

Harris F 2009 Perspectives on educational visits to farms. Final report of research for Ernest Cook Trust Kingston University

Harris F, Lyon F and Clarke S 2009 Doing interdisciplinarity: motivation and collaboration in research for sustainable agriculture in the UK Area 41 374-84

Hulme M 2010 Problems with making and governing global kinds of knowledge Global Environmental Change 20 558-64

Jennings $\mathbf{N}$ and Hulme M 2010 UK newspaper (mis)representations of the potential for a collapse of the Thermohaline Circulation Area 42 444-56

Maddrell A 2010 Academic geography as terra incognita: lessons from the 'expedition debate' and another border to cross Transactions of the Institute of British Geographers NS 35 149-53

Martin R 2001 Geography and public policy: the case of the missing agenda Progress in Human Geography 25 189-210

Massey D 2001 Geography on the agenda Progress in Human Geography 25 5-17

Merriman P 2010 Creating an archive of geographical engagement Area 42 387-90

Murphy A B, de Blij H J, Turner II B L, Gilmore R W and Gregory D 2005 The role of geography in public debate Progress in Human Geography 29 165-93

Phillips R 2010 The impact agenda and geographies of curiosity Transactions of the Institute of British Geographers NS 35 447-52

RCUK nd Check list for completing the impact summary and pathways to impact (http://impacts.rcuk.ac.uk/cmsweb/ downloads/rcuk/impacts/ChecklistPathwaystolmpact.pdf) Accessed 6 December 2010

Ward K 2005 Geography and public policy: a recent history of 'policy relevance' Progress in Human Geography 29 310-19

Wilson G 2010 Multifunctional 'quality' and rural community resilience Transactions of the Institute of British Geographers 35 364-81 